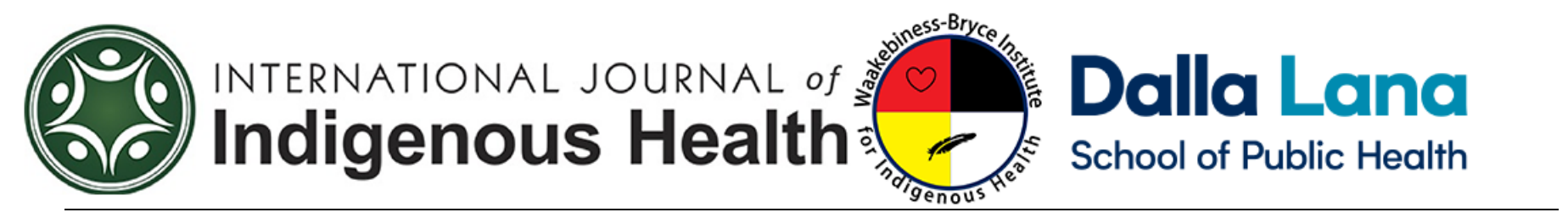

Volume 14

Issue 2. Growing Roots of Indigenous Wellbeing

Article 3

Full Issue DOI: 10.32799/ijih.v14i2.32958

October 2019

\title{
Self-Location and Ethical Space in Wellness Research
}

Cindy Peltier OCT, $\mathrm{PhD}$

Chair, Indigenous Education, Nipissing University, Schulich School of Education

cindyp@,nipissingu.ca

Louela Manankil-Rankin RN, PhD

Nipissing University, School of Nursing

louelam@nipissingu.ca

Karey D. McCullough RN, PhD

Nipissing University, School of Nursing

kareym@nipissingu.ca

Megan Paulin

Graduate Student, Nipissing University

mlpaulin893@.community.nipissingu.ca

Phyllis Anderson

Community-Based Researcher, Nipissing First Nation

phyljohn@personainternet.com

Kanessa Hanzlik

Community-Based Researcher, Nipissing First Nation

kenhanzlik@msn.com

Follow the International Journal of Indigenous Health at:

https://jps.library.utoronto.ca/index.php/ijih/index

\section{Recommended Citation:}

Peltier, C., Manankil-Rankin, L., Paulin M., Anderson, P., Hanzlik, K. (2019). Self-Location and Ethical Space in Wellness Research. International Journal of Indigenous Health, 14(2), 39- 53.

DOI:10.32799/ijih.v14i2.31914 


\title{
Self-Location and Ethical Space in Wellness Research
}

\begin{abstract}
Working with Indigenous communities involves responsibility, relationship, respect, and reciprocity (Kirkness \& Barnhardt, 2016; Peltier, 2018). Our research consists of a partnership with Nipissing First Nation to explore their citizens' understanding of wellness. Our aim is to tell a collective story of wellness based on the experiences of Nipissing First Nation citizens. As part of our relational research process, our research team engaged in an exercise of self-location in preparation for working with Nipissing First Nation stories. This process involved looking back into our own stories of wellness from three points in time as: children, youth, and adults. Our collective perspective of wellness involved three main themes of relationship, identity, and determinants of health. This exercise helped the researchers become aware of our own subjective lens about wellness. Awakening to our own stories helped us recognize the ethical space that existed between each of the researchers, the stories we will gather, and the perspectives of our community advisory committee. Engaging in this exercise illuminated our need for a continual reflexive stance, consistently being mindful about the privilege we hold as researchers and the invisible stories that creep into an analysis. The process of self-location was an essential element in the process of our research journey. It prepared us for working respectfully and reciprocally with the community that honours the ethical space we collectively share.
\end{abstract}

\section{Keywords}

Indigenous, Aboriginal, self-location, ethical space, wellness, reflexivity

\section{Acknowledgements}

This research was supported by the Canadian Institutes of Health Research Catalyst Grant in Indigenous Approaches to Wellness (CIHR Grant number 155891).

\section{Creative Commons License}

\section{(a) $\Theta \Theta \Theta$}

This work is licensed under a Creative Commons Attribution-Noncommercial-No Derivative Works 4.0 License. 


\section{Introduction}

Indigenous ways of being are relational and connect us to all of Creation, through physical and spiritual relationships with those who have gone before us, those still in this physical realm, and those spirits yet to come (Peltier, 2015; Peltier, 2018). Ways of knowing reflect how Indigenous peoples come to learn about these realms and are procured through relationships, languages, histories, spiritualities, and worldviews (Wilson, 2008). Similarly, Indigenous conceptions of living well are based in relationships, are deeply rooted in Indigenous languages, and derive from Creation stories (Peltier, 2015). Much of the research written about Indigenous peoples' health had been focused on Western, biomedical notions of a physical nature (King, Smith, \& Gracey, 2009) though there is a movement toward understandings of Indigenous notions of wellness which extend beyond a focus on physical health and illness (King, Smith, \& Gracey, 2009; Peltier, 2015).

To illustrate, the Anishinaabe concept of wellness is Mno Bimaadiziwin (the Way of a Good Life). This concept is multidimensional and emphasizes maintenance of balance in the four elements of a person's being: physical, emotional, mental, and spiritual. These four elements are often represented as components of the Medicine Wheel and have been used as a guide for understanding wellness (King, Smith, \& Gracey, 2009; Peltier, 2015). Based in an Anishinaabe relational way of being with family, community, all of Creation, the teachings of mno bimaadiziwin reinforce connections to all of Creation and describe a path for living well (Peltier, 2015).

Indigenous ways of knowing were once readily accessible through visits with Elders, knowledge keepers, and through participation in ceremony. Due to the effects of colonization, access and transmission of these ways of knowing to future generations is increasingly difficult. King, Smith, and Gracey (2009), noted that positive Indigenous identities are critical to wellness but colonial processes served to eradicate them. Communities are striving to reclaim these healthy identities based on strengths instead of deficits, disease burden, and discrimination (King, Smith, \& Gracey, 2009). "In spite of the considerable health issues and challenges ... [Indigenous] peoples continue to demonstrate resilience and strive for wellness based in Indigenous ways of knowing and being" (National Collaborating Centre for Aboriginal Health, 2013, p. 5). Our research project will inform reclamation of Nipissing First Nation's definition of wellness as well as processes for facilitating wellness from the voices of Nbisiing Debendaagziwaad (Nipissing citizens).

In this article, we discuss the initial relational phase of our research journey. We have mapped this journey onto the four R's of Indigenous research: responsibility, relevance, respect, and reciprocity (Kirkness \& Barnhardt, 2016). We also argue that this essential step lays the foundation for working in relationship with Nipissing First Nation and with each other. We are a group of Indigenous and diverse allied researchers who share how self-location (Absolon, 2011; Absolon \& Willett, 2004; Geniusz, 
2009; Hart, 2002; Kovach, 2009; Kovach, 2018; Lavallée, 2009; Linklater, 2014; McGregor, 2018; Peltier, 2018; Weber-Pillwax, 2004; Wilson, 2013) and Ermine's notion of the "ethical space of engagement" have influenced our work. This initial step in our research process awakened us to a deepened sense of reflexivity about our own socially situated narratives on wellness shaped by our diverse historical experiences of colonialism; so that we are able to hear our voices, and how they influence the co-construction of the stories gifted to us by Nbisiing Debendaagziwaad. This initial phase also centers on the Nbisiing concept of wiidooktaadyang, translated as "we are helping one another." This article reflects how we are helping one another to understand our own perspectives and to do our work in a good way.

\section{Demonstrating Our Responsibility in Self-Location}

We felt a shared responsibility to acknowledge our preconceptions about Indigenous wellness, what constitutes legitimate knowledge (Aveling, 2012), and how these beliefs will shape our understandings of wellness. We prioritized the self-location process and emphasized the critical importance of engaging in this process prior to any engagement with Nbisiing Debendaagziwaad stories and conceptions of wellness. We felt that this relational process paves the way for our collaborative work in examining how our worldviews shape the way we understand and interpret the stories we are gathering.

We acknowledge the historical, social, and cultural contexts that shape and story our lives (Manankil-Rankin, 2016). Particularly essential is to bring visibility to our cultural ways of knowing and the intersection of our Anishinaabe, Mi'kmaq, Canadian, Franco-Ontarian, Polish, Czech, and Filipino heritages. Our process of self-location took us to our past; reflecting on how stories from our memories influenced our present that, in turn, will inform our future. This process builds on Dewey's (1938) notion of interaction and continuity that suggest human beings understand the world through their interactions and that these perceived experiences are connected and continuous. From an Indigenous ontological and relational perspective, Elders have shared that our experiences are tied to relationships with our past, present, and future as "strings of lives connecting us to our ancestors and to those yet unborn" (Dumont \& National Native Addictions Partnership Foundation, 2014, p. 9). Reflecting on our past sheds light on aspects of life that help us see the social world and ourselves more clearly. Kovach (2009) shared that, "in co-creating knowledge, story is not only a means for hearing another's narrative it also invites reflexivity into research" (p. 100). We expect that this reflection will provide us with an understanding of our connectedness to the research question, and to one another as a research team, ultimately shaping our openness to listen to others' stories of wellness. It is this understanding that will allow us to co-construct a collective story with the participants to illuminate the Nbisiing Debendaagziwaad understanding of wellness. 


\section{Methods}

Our research team conducted a self-location activity that involved reflecting on our own stories of wellness from three different points in our lives-as children, as youth, and as adults. We told these wellness stories as if we were there in the moment, observing these experiences from the background, as bystanders of our own stories. We wrote individually, in the solitude of our own personal spaces, so that we could reflect on our past and think about how it may have informed our current understandings of wellness. We gathered to share our individual stories with each other-sharing our own and listening to one another's stories. We mapped the story elements on a whiteboard that helped to capture the resonant threads across all stories. These resonant threads served as plotlines to our emergent collective story (Clandinin, 2013; Clandinin \& Connelly, 2000). Reflective of the meaning-making process that will be undertaken with the participants' stories, we explored the resonant threads that emerged from our six individual stories as researchers. From these resonant threads, we created our own collective story (Peltier, 2015) of wellness. We argue that through this process of coming to our own collective story of wellness as researchers, we are able to be aware of what influences our own perceptions of the research questions, as well as how this lens will coalesce with the community participant narrative in the process of co-construction.

\section{Working in Relationship and with Relevance to Nipissing First Nation}

Nipissing First Nation is a community striving to reclaim their original ways of knowing and being. The Nbisiing concept, wiidooktaadyang describes a 'no wrong door,' wrap-around, community approach to service delivery, which values individual and collective responsibility. Framed as a supportive network of family, friends, and neighbours the wiidooktaadyang approach ensures the active engagement of community service programs aiming to minimize structural barriers through a context that is culturally safe. Supported by community leadership and fostered through collaboration, the wiidooktaadyang approach is rooted in Nbisiing ways of being. Internal partnerships with community services are cornerstones. The overall goal of wiidooktaadyang is for Nbisiing Debendaagziwaad to receive the appropriate kind of help when necessary through an all-encompassing approach to wellness guiding service delivery. The wiidooktaadyang approach to helping is in the initial stages of implementation within Nipissing First Nation.

Early consultations with community leadership, Elders, and knowledge keepers revealed that an examination of how Nbisiing Debendaagziwaad understand and experience wellness might further inform the wiidooktaadyang approach. A second area of interest would be to explore what Nbisiing Debendaagziwaad considered to be the 'appropriate kind of help' to facilitate wellness and how this knowledge could be translated to inform the current wiidooktaadyang model. Community-based 
initiatives such as the wiidooktaadyang approach and the research necessary to support them must be rooted in community values, knowledge, and history.

To frame our project within a relational context, Nipissing First Nation is an Anishinaabe community whose citizens are of Nipissing, Ojibway, and Algonquin descent. Nipissing's ancestors Shabogesic, Penassy, and O'jeek were signatories to the Robinson-Huron Treaty of 1850 (Couchie, 2012). The principal investigator is a 'researcher-in-relation' (Graveline, 2000; Kovach, 2010) with familial ties to Nipissing and ancestral leader, Shabogesic and this is, in part, related to the self-location or positioning of the researchers respectfully requested in this research partnership.

\section{Results}

\section{Respectfully Sharing Our Story of Collaboration}

We sought to afford both respect and dignity to all storytellers throughout the exercise of sharing our stories. Much of the sharing was personal and rich, reflecting both positive and negative experiences. As we listened to each other, we found ourselves arriving at a place of appreciation for the stories shared. The collective story composed, emerged from our own personal experiences of wellness and outlined our assumptions of this concept. Justifying this practically with the literature on wellness, using both Indigenous and Western ways of knowing, we arrived at our conceptual understanding of wellness derived from our self-location.

It was essential that the stories, although individually shared, were considered to be part of a composite (He, 2003) or a collective story (Peltier, 2015). Consistent with the use of composite stories in narrative inquiry, a composite intends to protect the anonymity of individuals in the story (He, 2003). The sharing of the personal stories in our small group of researchers required privacy and safety. A composite allowed us to illuminate the narrative threads that bound us together, and through our collective story, we are able to relate our emerging concept of wellness from both our personal experiences and the literature.

\section{Our Wellness Story}

My mother was single and 17-years old when I was born. She was the first born of a large family. From the time of birth, my mother had nine siblings and I grew up with them. After me, seven more siblings were born into our family of eighteen. I always felt my grandparents were exceptional to have made room for one more and gave me the teaching that we do not give our children away. My mother married when I was six and she did take me to live with them for a while. My mother told me that I went into some sort of depression and my grandmother 
instructed my mother to bring me home. It was evident that I missed my brothers and sisters because I spent the first six years of my life with them. Today, I live for my children. I work, play, exercise, eat, and love mostly for my kids. They define much of who I am today.

Growing up was a confusing time. I learned what the elementary school textbooks taught us about Indigenous peoples - Christopher Columbus arrived to discover uncivilized, ignorant, savages. From these experiences, I had a feeling of being dirty or lesser than. This dirtiness then grew into shame, shame of having dark hair and tanned skin. I had no knowledge of any of my heritages or cultures. We sang "O Canada" every morning but I did not know I was Canadian. I could speak two languages fluently but I did not understand what it meant to be a FrancoOntarian. I guess you can say I was lost growing up, not knowing where I belonged despite having knowledge of my Anishinaabe, Czech, and FrenchCanadian cultures. I always remembered how these books described Indigenous peoples when the Europeans arrived. I began feeling anxious, trying to dig deep into my emotions, some days I felt trapped and alone, feeling like no one understood me. On the outside, I was still the same happy, nice, and caring person. It was like riding a wellness rollercoaster.

I remember one summer we returned to our camp to find that there was a clear-cut of all trees in the area. We were no longer able to access the land that the Crown had promised never to privately sell. I cannot remember how old I was, but this was my first experience with grieving. I sat on the steps of the sleep cabin and cried and cried. I longed for the trails that I so intimately knew, the large rock I would picnic on during sunny afternoons, and the blueberry patches we picked from for generations. Those trees and plants were my friends. Growing up you also learn about relationships, how you are connected to the land, your relationships to the birds, animals, the water, everything in Creation, including relationships to your family-your brothers, sisters, aunties, and uncles. When my daughters were born, I told myself I was going to break the cycle of trauma. Today, I make sure we spend time on the land, that they hear Creation stories, that they are proud of their ancestry. I approached my uncle to assist me in finding my Anishinaabe name and clan. My learning about truth began with learning what my gifts and talents are and how I should use them to help others.

I started to pay more attention to my physical fitness and nutrition in order to maximize my physical performance in sports. I ran in several races and felt a 
special responsibility to my community and this was a form of wellness. Looking back, I feel fortunate that I have never had to be hungry but I do not know if my friend who lived across the street ever had anything to eat. I know that in my neighborhood people asked for contributions of food to help one another survive. As I think about my friend and the way she lived, I cannot help but think that housing also has something to do with being healthy. Her family did not have a house like mine. She lived in the bottom of an already established house-picture a hut on stilts. My friend's family created a makeshift house under this established house. She had to bend to get into her house.

Today, witnessing my parents growing old, I often wonder whether care or wellness means having access to all these specialists, or should care be a step further where one health care provider pulls the plans together. Is quality of life at this stage about enjoying the stillness of life; spending time with family; having a social life and managing illness symptoms? Is wellness also about experiencing peace rather than participating in ongoing appointments and not finding enough time to rest and to be still? Is peace both internally and externally the determinant of wellness? From my perspective, it is.

"Wellness from an Indigenous perspective is a whole and healthy person expressed through a sense of balance of spirit, emotion, mind and body. Central to wellness is belief in one's connection to language, land, beings of Creation, and ancestry, supported by a caring family and environment" (Dumont and the National Native Addictions Partnership Foundation, 2014, p. 2). Our team's perspective on wellness closely maps onto this definition of wellness and emerged from sharing our own personal stories and experiences across life stages-as children, youth and adults. Through our sharing of our stories of wellness, three main plotlines for our collective story emerged: relationships, identity, and the determinants of health. Relationships consisted of experiences of interactions with our families, communities, Western systems of health and education, Indigenous knowledge systems, and aspects of Creation including the land. Experiences of identity formation occurring within the context of these relationships further contributed to the way we expressed and defined wellness and became a key plotline in our collective story. Knowledge of where we came from helped to shape and form each our identities that, in turn, contributed to our sense of wellness whether expressed as family, professional, personal or cultural identity.

A culture is a self-identity related to the age or generation of a person, gender, sexual orientation, occupation, religious beliefs, or disabilities (McCullough, 2016). From an Indigenous perspective, our wellness story also reflected a definition of culture inclusive of the concepts: the circle, harmony and balance, all my relations, kindness/caring/respect, and the path of life continuum (Dumont and the 
National Native Addictions Partnership Foundation, 2014). Understanding our collective story of wellness through the notion of cultural identity was an essential part of positionality and self-location within this research project. The third key plotline in our collective story concerned the global concept of "determinants of health." Allied researchers have framed this concept as the "social determinants of health" while Indigenous researchers have highlighted Indigenous-specific determinants of health (Loppie Reading \& Wien, 2009; Peltier, 2015; Reading, 2015). Together, the two conceptualizations of determinants of health helped us to make visible a more expanded perspective and its influence on wellness, namely physical health, poverty, cultural continuity, and peace. Figure 1 below is a representation of what we came to understand as our story of wellness.

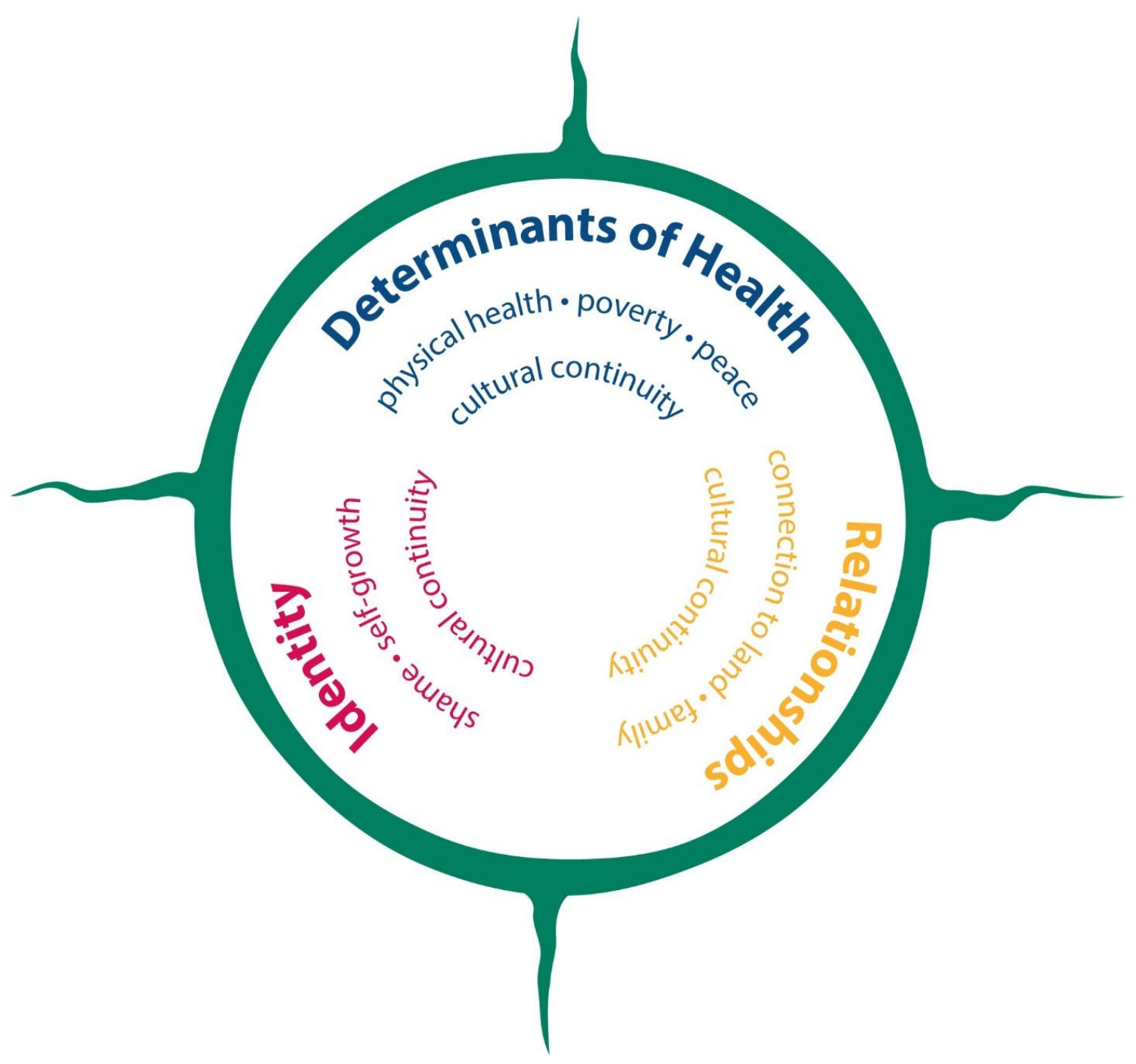

Figure 1. Our story of wellness 


\section{Discussion}

Self-location is an important part of the trust-building process between researchers and communities but it also allows for researchers, Indigenous and allies alike, to acknowledge biases and preconceived views about the research topic or populations of interest. The concept of self-location has been embraced within Indigenous research circles as a form of relational accountability (Absolon, 2011; Absolon \& Willett, 2004; Geniusz, 2009; Hart, 2002; Kovach, 2009; Kovach, 2018; Lavallée, 2009; Linklater, 2014; McGregor, 2018; Peltier, 2018; Weber-Pillwax, 2004; Wilson, 2013). Graveline (2000) and Kovach (2010) have used the terms "self-in-relation" and "researcher-in-relation" to describe researchers who define their work in terms of personal experiences, families, clans, communities, and nationhood. In the Anishinaabe way of being, "all my relations" encompasses both physical relationships as well as ties to the spiritual realm. Our work honours this Anishinaabe way of beinglocating ourselves in a respectful and accountable manner to Nipissing First Nation but also to the wider academic community as we situate ourselves and our work within this wider context.

We believe that it is important to locate ourselves for another important reason. A respected knowledge keeper once shared that persons sharing knowledge should be able to say where they received that gift and by what authority they have been given to share that gift. "I used to listen to them and they explained where they got this gift, how they got it, what they went through to get this gift" (Peltier, 2015, p. 205). If we enter into a respectful relationship, we should acknowledge who we are and what knowledge we can share about a topic. We might have received this knowledge from the scholarly literature, or from our own personal life experiences and engagement with that topic. As Indigenous academics share, "our story as researchers begins with the source(s) of our knowledge, not only those direct sources that contribute to a current project, but also those individuals and life experiences that along the way have shaped who we are" (McGregor, 2018, p. 245). While these may not seem to fit within the 'academic' ideals of knowledge like scholarly literature, from an Indigenous research perspective it is essential that we acknowledge all sources of knowledge, including our own perspectives of the research topic (Geniusz, 2009; McGregor, 2018) grounding our work from self-location and establishing relationships.

Indigenous peoples have expressed skepticism about participating in research due to past adverse experiences, and an inability to trust researchers (Blair, 2016; Castellano, 2014; Peltier, 2018). As such, some non-Indigenous, allied researchers have questioned their role and legitimacy in Indigenous research citing a fear of appearing exploitive of Indigenous peoples, or undermining Indigenous selfdetermination (Aveling, 2012). While this sheds a different light on the process of self-location for our allied partners, as researchers we have found common ground -that is, establishing and nurturing relationships with community by remaining relationally accountable, transparent, and truthful about our positions, and how they invariably influence the rest of our work. 


\section{An Ethical Space of Engagement for Our Collaborative Research}

We realized as a group that we had arrived at a shared conception of wellness despite our different backgrounds. Our stories of wellness, across time, were congruent with one another. Each of us spoke from our own past and present stories about relationships, identities, and determinants of health as they contribute to our understanding of wellness. Through our historical, social, and cultural contexts, we imparted stories woven from our experiences of life that resonated with each other. It was at that point we realized that we entered into a space of deep engagement. We sensed that we were in a place of readiness where we could move forward in humble presence to listen with openness to the stories of the Nbisiing Debendaagziwaad.

This was particularly significant in our process as researchers, as we brought our voices to the foreground. This is consistent with Chase (2005), who suggests that a researcher's examination of her/his voice allows for locating of positions that identifies particularities of experience. Muhammad, Wallerstein, Sussman, Avila, Belone, and Duran (2015), claim that the researcher team's awareness of their team's identity is of importance when conducting community-based participatory action research. Examining and revealing this team identity is an essential component of conducting this methodology. Reflecting on our team's experiences of wellness and its contributing influence to our collective story of this concept makes us cognizant of the influence of intersubjectivity. While stories emerge from coconstruction, awareness of our social location and position helps us to be careful of the invisible author of community stories in all of us as well as the stories we privilege (Chase, 2005; Muhammad et al., 2015).

Indigenous scholar Willie Ermine (2007) adds to the clarity of our experience more deeply through the idea of ethical space. He described a metaphorical space created from interactions between individuals of different worldviews. In this space, allegiances and mental constraints dissipate for the purpose of reconciling differences and hearing each other. While Ermine (2007), used the legal contexts and differences between Indigenous and Western perspectives when he initially described this space, our journey in engaging within the metaphorical meeting place of ethical engagement is to address exactly what Ermine suggests-to dialogue in a cooperative spirit. Our conversations, at times were awkward, but they moved us further into deeper dialogue about the meaning of our experiences and encouraged us to strive to be transformative and embrace diversity. Our experience opened a safe space for conversation about our differences in worldview and positionality.

Essential to the discussion is the awareness of the ethical space between researchers and the Community Advisory Committee overseeing this research project. As researchers, we have an obligation to engage in ongoing reflexive practice that ensures the recognition of community voice as a coconstructor of the overarching story of wellness and a true research partner. This is consistent with 
Indigenous scholars who advocate that research conducted with Indigenous communities is responsible, relevant, respectful, and reciprocal (Kirkness \& Barnhardt, 2016).

Our work in this ethical space influenced how we co-constructed our story of wellness and our relationship with one another as researchers and with the community. Our renewed sense of understanding about wellness based on our shared conceptualization awakened us to a new perspective.

\section{Conclusion}

\section{Reciprocal Impacts for Communities, Allied, and Indigenous Researchers}

Every research project should aspire to meet the primary objective of creating respectful and ethical research with Indigenous communities. Moreover, a project may also strive to be transformative and reciprocal where we learn lessons in embracing diversity. Transforming research in this initial phase of our current project involved opening a safe space for dialogue about differing worldviews, our beliefs and understandings concerning wellness. We are mindful that transparency in this process is key. It is important to note that engaging in this metaphorical space was not always an easy process and that it is equally important to acknowledge the relational tensions, "pauses, critical reflections, and seemingly awkward conversations" (Morton, Ninomiya, \& Pollock, 2016, p. 29) with an intent to offer guidance for future researchers. Despite some challenges, this process of sharing our stories and conducting this reflective work in this ethical and relational space has helped us to understand one another. The process will ultimately inform our upcoming process of meaning making from the stories of Nbisiing Debendaagziwaad. It is in the unpacking of the stories that we begin to see where we are as individuals, and collectively, as a team in relation to this research journey.

Arriving at our collective story helped us see how we experience wellness through the lenses of our past, present, and future. Doing so, in this relational, ethical space will allow us to approach the participants' stories with humility and openness. The product of this research will be a collective story of wellness reflecting the stories of Nbisiing Debendaagziwaad. The resulting story is a co-construction from multiple perspectives, Nbisiing Debendaagziwaad, the community advisory committee, and the research team. Doing this work in advance allows us to discover ourselves within the context of our historical, social, and cultural storied lives. This exercise prepares us for working reciprocally with an awakened perspective of how our self-location and position influence the way we engage subjectively with each other. The process helped us to enter the ethical space respectfully and be mindful of the privilege we hold as researchers. 


\section{References}

Absolon, K. (2011). Kaandossiwin: How we come to know. Halifax, NS: Fernwood Publishing.

Absolon, K. \& Willett, C. (2004). Aboriginal research: Berry picking and hunting in the 21st century. First Peoples Child \& Family Review, 1(1), 5-17. Retrieved from: http://journals.sfu.ca/fpcfr/index.php/FPCFR/article/view/5/2

Aveling, N. (2012). Don't talk about what you don't know: On (not) conducting research with/in indigenous contexts. Critical Studies in Education, 54(2), 203-214. doi.org/10.1080/17508487.2012.724021

Blair, N. (2016). Researched to death: Indigenous peoples Talkin' Up our experiences of research. International Review of Qualitative Research, 8(4), 463-478. doi.org/10.1525/irqr.2015.8.4.463

Castellano, M. B. (2014). Ethics of Aboriginal research. In W. Teays, J-S. Gordon, \& A. Dundes Renteln (Eds.). Global Bioethics and Human Rights: Contemporary Issues (pp. 273-288). Lanham, MA: Rowman \& Littlefield.

Chase, S. E. (2005). Narrative inquiry: Multiple lenses, approaches, voices. In N. K. Denzin \& Y. S. Lincoln (Eds.). The Sage handbook of qualitative research, third edition, (pp. 651- 679). Thousand Oaks, CA: Sage Publications, Inc.

Clandinin, D. J. (2013). Engaging in narrative inquiry. Walnut Creek, CA: Left Coast Press, Inc.

Clandinin, D. J., \& Connelly, F. M. (2000). Narrative inquiry: Experience and story in qualitative research. San Francisco, CA: Jossey-Bass.

Couchie, M. (2012). Nipissing First Nation. Retrieved from: https://www.fnmhf.ca/english/participating_fn/participating_fn_030.html

Dewey, J. (1938). Experience and education. New York: Touchstone.

Dumont, J., \& National Native Addictions Partnership Foundation. (2014). Honouring our strengths: Culture as intervention in addictions treatment reference guide. University of Saskatchewan, Canada. Retrieved from http://www.addictionresearchchair.ca/wpcontent/uploads/2012/04/FINAL-ReferenceGuide_June25_DIGITAL.pdf

Ermine, W. (2007). The ethical space of engagement. Indigenous Law Journal, 6(1), 193-203. Retrieved from https://jps.library.utoronto.ca/index.php/ilj/article/view/27669

Geniusz, W. M. (2009). Our knowledge is not primitive: Decolonizing botanical Anishinaabe teachings. Syracuse, NY: Syracuse University Press. 
Graveline, F. J. (2000). Circle as methodology: Enacting an Aboriginal paradigm. International Journal of Qualitative Studies in Education, 13(4), 361-370. doi.org/10.1080/095183900413304

Hart, M. (2002). Seeking mino-pimatisiwin: An Aboriginal approach to helping. Halifax, NS: Fernwood Publishing.

He, M. F. (2003). A river forever flowing: Cross-cultural lives and identities in the multicultural landscape. USA: Information Age Publishing Inc.

King, A., Smith, A., \& Gracey, M. (2009). Indigenous health part 2: The underlying causes of the health gap. The Lancet, 374(9683), 76-85. doi.org/10.1016/S0140-6736(09)60827-8

Kirkness, V., \& Barnhardt, R. (2016). First Nations and higher education: The four R's — respect, relevance, reciprocity, responsibility. Journal of College and University Student Housing, 42(2), 94-109. Retrieved from http://www.nxtbook.com/nxtbooks/acuho/journal_vol42no2/ - /96

Kovach, M. (2009). Indigenous methodologies: Characteristics, conversations, and contexts. Toronto, ON: University of Toronto Press.

Kovach, M. (2010). Conversational method in Indigenous research. First Peoples Child \& Family Review, 5(1), 40-48. Retrieved from http://journals.sfu.ca/fpcfr/index.php/FPCFR/article/view/172

Kovach, M. (2018). Doing Indigenous methodologies-A letter to a research class. In N. K. Denzin \& Y. S. Lincoln (Eds.), The SAGE handbook of qualitative research, 5th ed., (p. 214-235). Los Angeles, CA: SAGE Publications.

Lavallée, L. F. (2009). Practical application of an Indigenous research framework and two qualitative indigenous research methods: Sharing circles and Anishnaabe symbol-based reflection. International Journal of Qualitative Methods, 8(1), 21-40. doi.org/10.1177/160940690900800103

Linklater, R. (2014). Decolonizing trauma work: Indigenous stories and strategies. Halifax, NS: Fernwood Publishing.

Loppie Reading, C., \& Wien, F. (2009). Health inequalities and social determinants of Aboriginal peoples' health. Prince George, BC: National Collaborating Centre for Aboriginal Peoples' Health. Retrieved from https://www.ccnsa-nccah.ca/docs/determinants/RPT-HealthInequalities-ReadingWien-EN.pdf

Manankil-Rankin, L. (2016). Moving from field text to research text in Narrative Inquiry: A study exemplar. Canadian Journal of Nursing Research, 48(3-4), 232-239. doi.org/10.1177/0844562116684728

McCullough, K. (2016). The process involved in international preceptorship in undergraduate nursing education (Unpublished doctoral dissertation). University of Alberta, Edmonton, Canada. 
McGregor, D. (2018). Toward an Anishinaabe Research Paradigm: Theory and Practice. In D. McGregor, J. P. Restoule \& R. Johnston (Eds.). Indigenous research: Theories, practices, and relationships, (p. 243-256). Toronto, ON: Canadian Scholars.

Ninomiya, M., \& Pollock, N. J. (2016). Reconciling community-based Indigenous research and academic practices: Knowing principles is not always enough. Social Science and Medicine, 172, 28-36. doi.org/10.1016/j.socscimed.2016.11.007

Muhammad, M., Wallerstein, N., Sussman, A. L., Avila, M., Belone, L., \& Duran, B. (2015). Reflections on researcher identity and power: The impact of positionality on community based participatory research (CBPR) processes and outcomes. Critical Sociology, 41(7-8), 1045-1063. doi.org/10.1177/0896920513516025

National Collaborating Centre for Aboriginal Health. (2013). An overview of Aboriginal health. Retrieved from:

https://www.nccih.ca/495/An_Overview_of_Aboriginal_Health_in_Canada.nccah?id=101

Peltier, C. (2015). The lived experience of Anishinaabe people with cancer: A focus on Indigenous healing, Western medicine and Minobimaadiziwin (Unpublished doctoral dissertation). Laurentian University, Sudbury, Canada.

Peltier, C. (2018). An application of Two-Eyed Seeing: Indigenous research methods with participatory action research. International Journal of Qualitative Methods, 17(1), 1-12. doi.org/10.1177/1609406918812346

Reading, C. (2015). Structural determinants of Aboriginal Peoples' health. In M. Greenwood, S. de Leeuw, N. Lindsay \& C. Reading (Eds.), Determinants of Indigenous Peoples' health: Beyond the social (pp. 3-15). Toronto, ON: Canadian Scholars' Press.

Weber-Pillwax, C. (2004). Indigenous researchers and Indigenous research methods: Cultural influences or cultural determinants of research methods. Journal of Indigenous Wellbeing Te Mauri Pimatisiwin, 2(1), 77-90. Retrieved from https://journalindigenouswellbeing.com/volume-2-1spring-2004/indigenous-researchers-and-indigenous-research-methods-cultural-influences-orcultural-determinants-of-research-methods/

Wilson, S. (2013). Using Indigenist research to shape our future. In M. Grey, J. Coates, M. Yellow Bird, T. Hetherington (Eds.). Decolonizing Social Work (p. 311-322). Burlington, VT: Ashgate Publishing.

Wilson, S. (2008). Research is ceremony: Indigenous research methods. Halifax, NS: Fernwood Publishing. 